\title{
Geolocating Ottoman Settlements: The Use of Historical Maps for Digital Humanities
}

\author{
Jilian $\mathrm{Ma}^{\mathrm{a}, *}$, Akın Sefer ${ }^{\mathrm{a}}$, M. Erdem Kabaday ${ }^{\mathrm{a}}$ \\ ${ }^{a}$ KoçUniversity,jma19@ku.edu.tr, aksefer@ku.edu.tr, mkabadayi@ku.edu.tr \\ * Corresponding author
}

\begin{abstract}
This paper aims to demonstrate and discuss the ways historical maps are used for geo-spatial and digital humanities, as well as their challenges, based on an ongoing project that aims to geolocate settlements in Ottoman Turkey, as registered in the mid-nineteenth century. As part of an ERC project, the project team has georeferenced historical maps of Asia Minor published by official institutions in the early twentieth century. Utilising these maps, the project team has been working on determining the present-day locations of Ottoman settlements as surveyed in the population registers of the 1840s and creating a geodatabase that aims to make the geographical and demographic information on these registers available and accessible to historians and social scientists. In the paper, we first introduce the Ottoman population registers and the ways we digitise and analyse these registers and then give a background on the maps we employ in these efforts. We then aim to explain the process of georeferencing these maps, the ways we bring together both the registers and the maps to locate these villages on the present-day maps, and the challenges/problems we encounter in this process. In the final part of the paper, we discuss how this project's end results could be employed for new questions, approaches, and debates in studies on modern Ottoman-Turkish history within the framework of perspectives developed in digital humanities.
\end{abstract}

Keywords: Ottoman Empire, Historical Maps, Geolocation

\section{Introduction}

Historical maps are valuable reference sources for our understanding of the past, bearing retrospective geographic information. This paper aims to demonstrate and discuss how historical maps are used for geo-spatial humanities and the challenges of doing so, based on an ongoing project that aims to geolocate all the settlements in Ottoman Anatolia, as registered in the mid-nineteenth century. As part of the ERC Project, UrbanOccupationsOETR, (Industrialisation and Urban Growth from the mid-nineteenth century Ottoman Empire to Contemporary Turkey in a Comparative Perspective, 1850-2000, urbanoccupations.ku.edu.tr), the project team has georeferenced German and Ottoman-Turkish historical maps prepared and published in the early twentieth century by official institutions. Using these maps the project team has been working on determining and geolocating Ottoman settlements' present-day locations as surveyed in the population registers of the 1830s and 1840s. In this process, through the QGIS, an open-source geographic information system (GIS) program, the population registers and historical maps are integrated into a demographic dataset that aims to make the information on these registers available and accessible to historians and social scientists. ${ }^{1}$ This paper will outline the geolocation efforts and their challenges in this process and then discuss how the geodatabases produced as part of these efforts could further our understanding of the social and economic history of the Ottoman Empire.

\subsection{Population Registers, Historical Maps, and Geolocation}

In this research, as our main primary sources, we use the Ottoman population registers compiled in the 1830 s and the 1840s. For our purposes, we focus on all settlements located on the western half of present-day Turkey (west of about $34^{\circ} \mathrm{E}$ ). These registers are in jpeg format and available from the Department of Ottoman Archives in the Turkish Presidency State Archives (BOA. NFS.d. catalogue series). There are currently around 11,000 population registers catalogued in the Ottoman archives, covering Asia Minor and the Ottoman Balkans

\footnotetext{
${ }^{1}$ We already started to share selected datasets and visualizations at urbanoccupations.ku.edu.tr/publicdatasets/
} 
geographically. These sources were made available relatively recently in 2011, and therefore their huge potential has not yet been exhausted by historians of the Ottoman Empire. The registers provide detailed information of each male inhabitant in every household, including names, ages, family relations, occupations and data on birth, death and migration. Usually, the registers were compiled based on a kaza, a sub-district, (smaller than NUTS-3 and compatible with LAU-1 level for modern Turkey) administered originally by a judge ( $\mathrm{kad} l$ ), and following the mid-nineteenth century bureaucratic reforms, by a town administrator (kaymakam or kaza müdürï). In the Ottoman administrative hierarchy, few or several kazas formed a province (sancak or vilayet). Often each register recorded a single district divided into a city or town and the surrounding villages. The usual practice records Muslims and non-Muslims of the same kaza in different registers, though in many cases, one can find nonMuslims recorded in the same register with Muslims, especially in places where the former were a minority (For a detailed introduction of the population register and its mechanism in the late Ottoman Empire, see Shaw, 1978). By means of these registers, we have created a database consisting of information not only on the number of male subjects and the total number of households in each location but also on the demographic distribution of this population across various categories. In addition to ethnoreligious differences, the registers also provide detailed information that reflected official differentiation between residential (yerli) and non-residential (yabancl) groups. The latter group of people were also differentiated among themselves, across their residential units, tribal belonging, or particularly in cases with substantial numbers of labour migrants, their occupations. As a result, geolocating these places create a unique opportunity to conduct data-driven studies on how spatial factors entangled with socioeconomic, demographic, and cultural processes in the midnineteenth century Ottoman Empire.

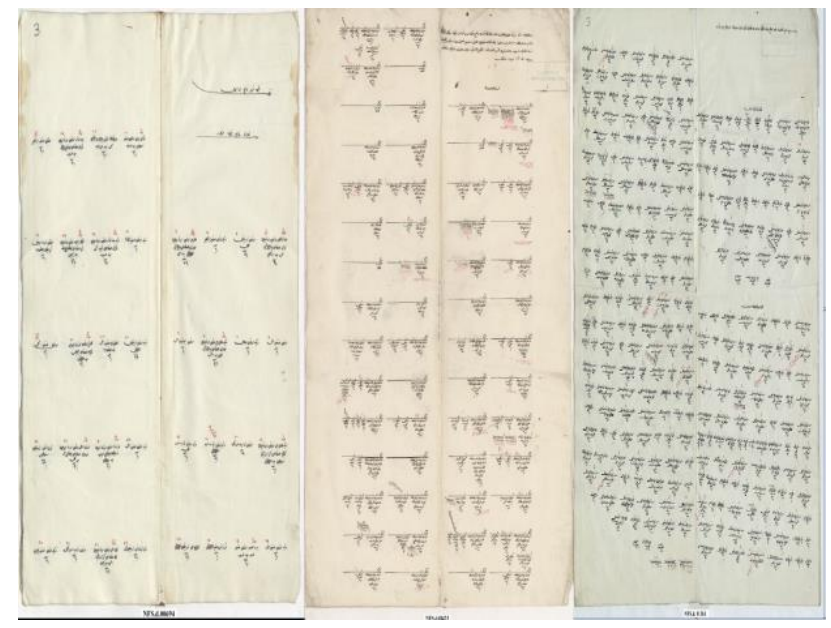

Figure 1. Samples of different layouts of the registers (from BOA.NFS.d. 694; NFS.d. 1423; and NFS.d. 1361 respectively, from left to right).
Based on these registers, we try to find and locate the geographical units as recorded within each kaza. These units most commonly refer to villages, complemented by a city/town at the centre and at times by çiftliks (farms), Ottoman (often export-oriented) agricultural units. Unfortunately, locating a nineteenth-century geographical unit is a task full of challenges and problems, first and foremost due to the nonexistence of an Ottoman gazetteer and secondly to the lack of detailed maps that systematically recorded village-level units in the midnineteenth century Ottoman Empire. Since systematic efforts in this regard were launched rather later, the cartographical sources we use are dated back to the late nineteenth and early twentieth centuries. One of the maps of this kind is the Karte von Kleinasien compiled by the German cartographer Richard Kiepert (1846-1915), under the far-reaching impact of his father, the famous cartographer Heinrich Kiepert. This is a 24-sheet series at a scale of 1:400,000, in which Anatolia was divided into 23 regions and mapped in separate sheets. Dietrich Reimer, between 1902 and 1906, first published it, and several revisions were made up to 1916 (Kiepert - TDV Islâm Ansiklopedisi; Talbert, 2019). Kiepert map of Anatolia is available online in several versions via numerous respected libraries. The glossary and legends are Ottoman Turkish in transliterated style. Another set of maps with the umbrella name "Türkei" from the Deutsche Heereskarte are also employed for georeferencing. They were produced by German military cartographers between 1941 and 1944 and revised in later years (Scharfe, 2003). Each sheet was named individually and based on separate original Turkish maps at a scale of 1:200,000. Various versions of the Deutsche Heereskarte are again available online via academic institutions, the largest of which is provided by the McMaster University library. Nevertheless, none of the online collections is complete for Turkey. Therefore, we obtained our digital copies of the Deutsche Heereskarte, Turkey, personally from the Austrian Federal Office of Metrology and Surveying's (BUV) Cartography Department / Historical Map Archive in Vienna. During WWII, the Deutsche Heereskarte of Turkey was produced by the German Oberkommando des Heeres in Vienna, and there is an institutional continuity in the archives of the BUV. The glossary and legends are in German and Turkish. In addition to these German map series, we also consult the Ottoman maps issued by the Erkan-ı Harbiye Umumiye Harita Heyeti (Map Committee of the Military Staff College) between 1910 and 1927. Ninety-four individual maps covering the main regions of Anatolia are referred. They are at a scale of 1:200,000, and the glossary and legends are in Ottoman Turkish (For the production of these maps, see Özağaç, 2006, pp. 59-82). 




Figure 2. Three sheets of maps from Karte von Kleinasien, Deutsche Heereskarte and Erkan-ı Harbiye series respectively, from top to down.

These three sets of maps are known to be the earliest systematic attempts to cover the entire Anatolia village by village. They are topographic maps showing professionally surveyed landforms, boundaries, locality names, and transportation lines, etc., in detail. Our project team georeferenced these maps. Together with contemporary maps and satellite images by various providers, they are imported to the QGIS program and configured as source layers to the QGIS canvas, serving as additional comparative tools for our geolocating procedure.

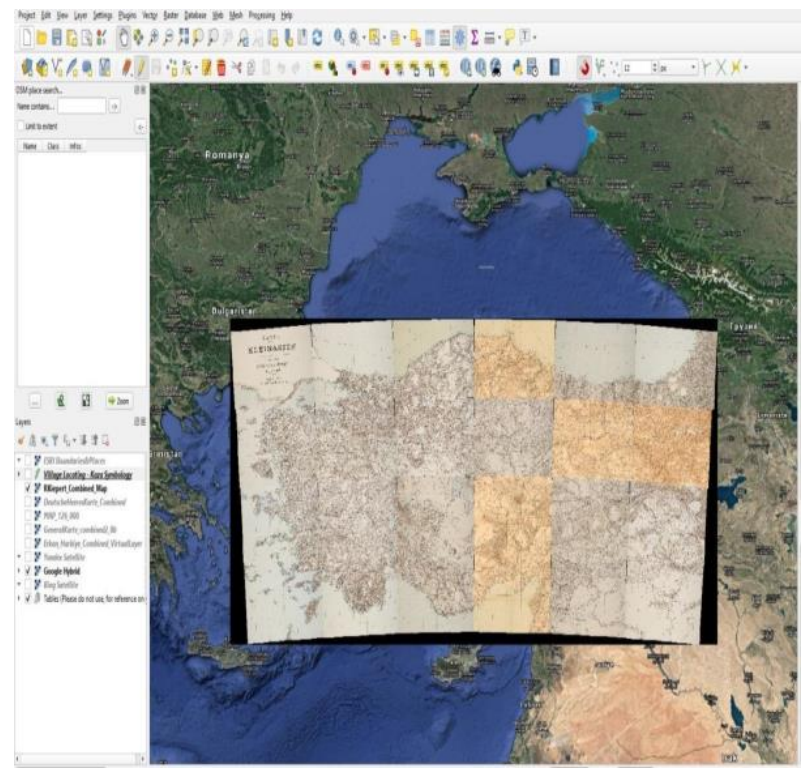

Figure 3. A combined overall Karte von Kleinasien as shown on the QGIS canvas. Deutsche Heereskarte and Erkan-ı Harbiye maps are combined in a similar way.

\section{Geolocating procedure}

For every village to geolocate, we extract its location information, register information, population and ethnoreligious information from the corresponding register. Location information includes the name of a settlement, the administrative units it belonged to at the time it was surveyed, and the location type of the settlement (town, village, etc.). These data are indicated in the headline of a particular settlement in the population registers. In addition to information on the register that we utilise for our purposes (e.g. its type, date, page numbers), we enter the demographic data we extract from the records. These include information on the total count of male individuals and their households, the official classification across their ethnic-religious belonging, and the categories mentioned above for non-residents. 


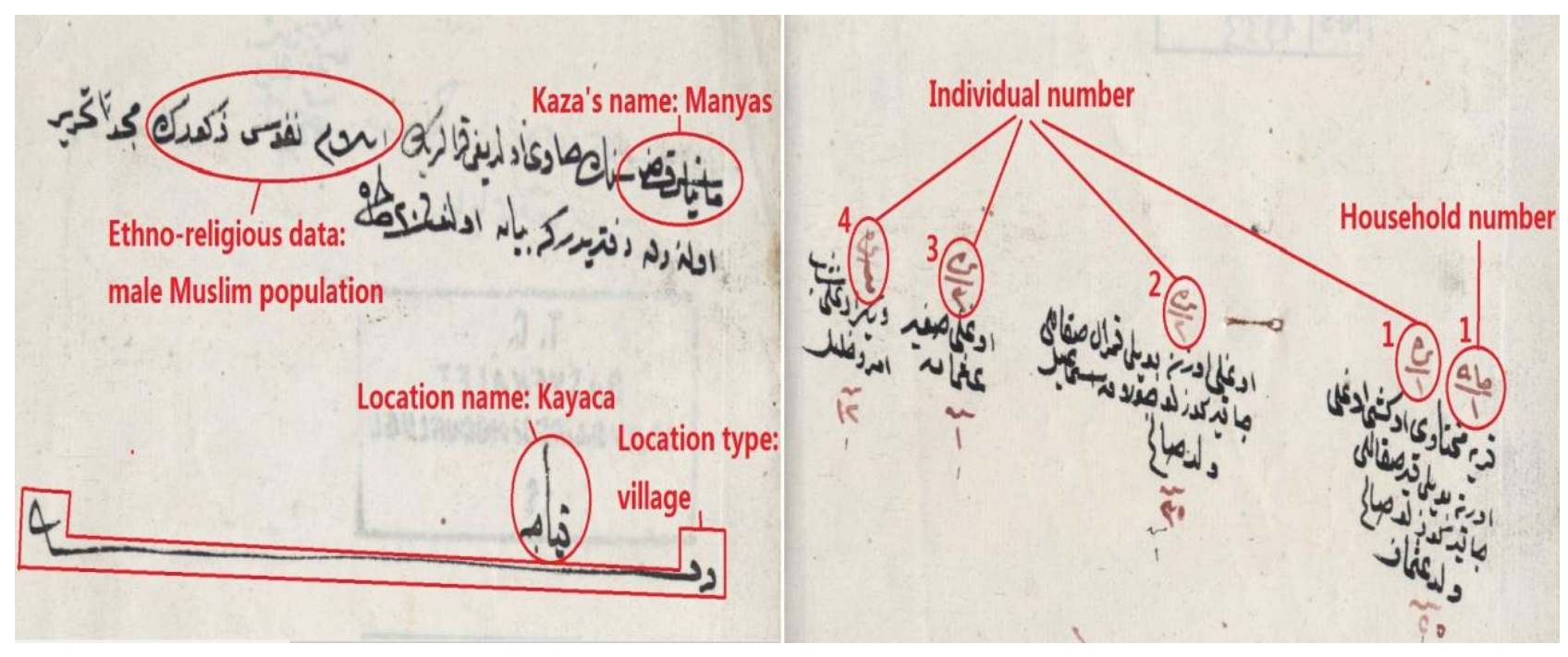

Figure 4. Extracting information from the register (BOA. NFS.d. 1333).

After extracting a particular village's name and its administrative division data from the register, we decide where to locate it. For those settlements that have survived to the present day with their original names on registers, this procedure is straightforward, as we follow its presentday location, though we still confirm that they were in the same place in the past. Our confirmation process starts first by considering how they were recorded on the register: In many cases, we can reveal a pattern where Ottoman census officials follow a certain geographical route in recording the villages, which records a settlement before or after a nearby one on the register. A complementary way to do so is to consult with the above-mentioned historical maps to confirm their presence at the same location in the early twentieth century. We also consider the fact that the original site of a settlement could be moved due to a catastrophic event (e.g. earthquakes or floods), the emergence of a town nearby with the same name, or the transformation of the landscape following the construction of a dam or a mine on the original location.

A more challenging task is locating the settlements that either totally disappeared or changed their names since the mid-nineteenth century. If these changes happened during the rest of the nineteenth century, we often could not locate such settlements. However, many among such settlements either disappeared or changed names during the first half of the twentieth century, mainly due to catastrophic population movements, including the Armenian Genocide and the Greek-Turkish population exchange, or the Turkification of several location names in this period. For the ones that disappeared, we locate them in reference to their stated location (if any) on the historical maps we use. For the ones that changed their names, we often consult with Index Anatolicus, the website of a database of historical and current names of locations across presentday Turkey (Index Anatolicus, 2021) and secondary historical literature on the area. In both cases, we try to confirm/support them with our historical map sources.
In cases where we can link a historical settlement's location with a current one, we locate it on its present-day location on a satellite image (as provided by Google, Yandex, or Bing). If the location's name no longer exists on present-day maps, we refer to the historical maps. We toggle one of the historical maps into an active layer in the QGIS canvas and attempt to pinpoint the village on the historical map by searching its vicinity according to its administrative division and comparing it with its previous and next settlement in the register. If this step is successful, we add a point feature to the layer and geolocate it. In this situation, we mark the location with an abbreviation of the map source, such as "KP" for Kiepert's Karte von Kleinasien, "DH" for Deutsche Heereskarte and "EH" for Erkan-ı Harbiye maps. For example, there are two villages named "Manastır" and "Tepecik" in the register of Karaburun kaza in the Suğla sancak. These names no longer exist on contemporary maps. The villages might have disappeared or been emptied due to an earthquake or other reasons. We resorted to historical maps and found that these two villages are shown on Kiepert's Karte von Kleinasien. Therefore, we marked their locations based on their records on the map and marked them with "KP" (See Figure 5). If the village's name exists on neither presentday nor historical maps, we enter the village's information to the attribute table without adding a point feature on the layer. In this way, we ensure a complete entry of all the settlements in the registers. Each time we add a point feature to the layer, a feature form appears, which is customised for data entry. We then transliterate the location information, register information, and population and ethno-religious information extracted from the register and enter them as the point's attributes in this form. Thus, we complete a basic geolocation procedure. Adding a point also yields the geographic coordinates of this village automatically. These data are recorded synchronously in the attribute table and therefore stored in the source data. 


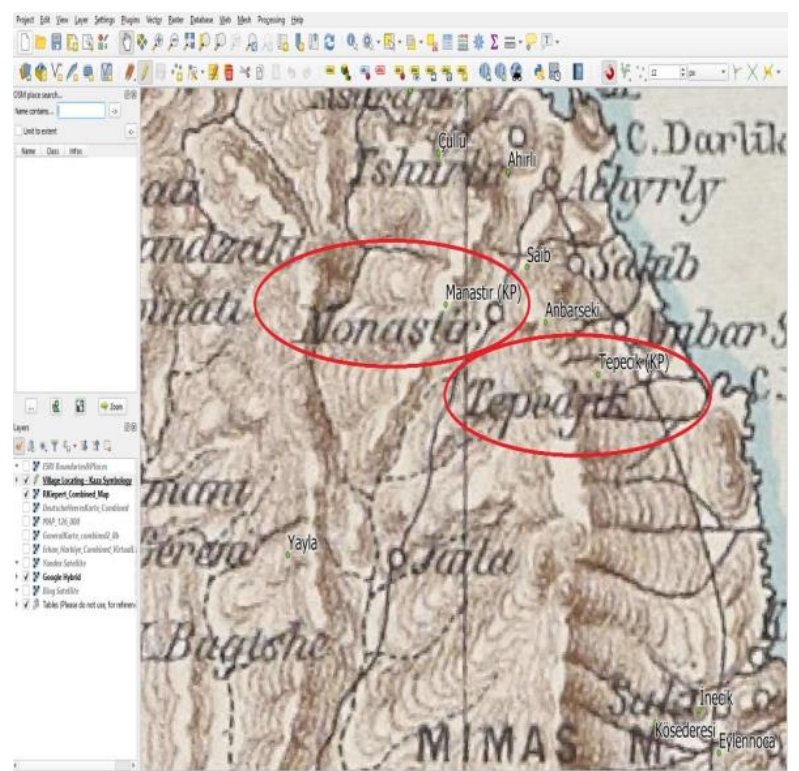

Figure 5. Geolocating the villages of Manastir and Tepecik based on their location on the Karte von Kleinasien.

A highly complicated and time-consuming process as such has been possible thanks to a collective effort that has brought several historians and GIS specialists together. Nevertheless, the challenges of this process are not limited to technical issues or to finding missing villages. In effect, the problems with the sources themselves could pose particular challenges during this process. To begin with, as the registers we consult were products of the first systematic population count in the Ottoman Empire, standards regarding registration were still not established, creating critical differences across different registers of the same location. These differences ranged from the absence of orthographic standards in registering the names to the variations in administrative belonging or in determining who/where to register and how. The lack of orthographic standards may pose particular risks for accurately locating a historical place, as a result of variations in spelling by different scribes in the era; challenges of differentiating names with similar spelling in Ottoman handwriting (e.g. if a village was named Dere (درم) or Dede (دده)); or inconsistencies, especially in Kiepert or Deutsche Heereskarte in transliterating Ottoman/Turkish names. Such problems are particularly challenging for finding or transliterating non-Turkish (mostly Greek and Armenian) place names accurately. Population registers varied in spelling them, just like early twentieth century maps did in transliterating them. In most cases, we have been able to overcome such problems through a comparative analysis of different sources and/or with the help of the secondary historical literature on the respective regions.

A particular challenge in geolocating Ottoman settlements through mid-nineteenth century population registers emanate from the fact that these registers were products of an era marked by a continuous overhaul of the administrative-bureaucratic structure of the Ottoman state. As part of the Tanzimat reforms in the 1840s, the administrative belonging or status of a specific location changed continuously, sometimes at a pace difficult to trace across different registers. But more importantly, for our purposes, a core aim of the Ottoman reform era was to sedentarise nomadic groups for tax-collection and conscription purposes. In line with historical studies that attributed this policy only a partial success, our registers mark this process's difficulties for Ottoman bureaucracy (Kasaba, 2009). The Ottoman registers of the era recorded some of these groups as "settled" in identifiable locations, predominantly an existing or newly-formed village, whereas they recorded the others as being located "around" or "nearby" a specific town or village. Even in the first case, which points out to a more permanent type of settlement, we need to approach such records cautiously, since historical studies we consult when geolocating a specific region suggest that in most cases, such villages did not remain permanent, and mobility continued to define the lifestyles of these nomadic groups. At times, our historical maps confirm this, as only some of these settlements appear as villages in the early twentieth century. Although we are unable to verify whether these became actual villages at the time of registration or rather far later in the late nineteenth century, we have opted to resolve this dilemma by taking the records for granted: Whereas we geolocated the first group of settlements as proper locations, we treated the second groups, which the Ottoman officials did not attribute a specific, identifiable location, as nomadic groups, rather than locations.

This brings us to a significant challenge posed by our cartographical sources. In line with the military purposes associated with these maps, and most likely due to varying geostrategic significance of different regions in Anatolia in different periods, these maps cover different parts of Anatolia in varying levels of detail. In other words, they could refrain from covering many of the villages in one region, whereas they could record even the smallest settlements (such as çiftliks) in another. Coupled with the peculiar characteristics of administrative divisions in certain areas, this has created difficulties in finding the present-day locations of historical settlements in such regions. An example in this regard can be shown through Western Black Sea settlements, where the Ottoman administrative division was marked by a distinct category called divan, an administrative unit that brings together a few villages. In most cases, the historical maps only locate the divans without specifying the locations of the villages within each division. In many cases, we can identify such villages' present-day locations through contemporary sources, at least if they have preserved their historical names today, either as the name of a village, neighbourhood, or a street. But there are also dozens of others which we, unfortunately, have failed to do so. 


\section{Discussion}

So far, we have processed the geographic and demographic data belonging to more than 10.000 settlements in the midnineteenth century, which covered more than 500.000 households and 1.3 million male subjects (Ottoman population registers record only males) living in the western provinces of Asia Minor. In this process, we not only transferred the data from the registers to the digital environment but also processed them in relational geodatabases by organizing, classifying and geolocating according to specific standards. Moreover, with the help of several secondary sources, these data were contextualized, revealing the historical changes experienced by these communities, ranging from the demolition of settlements to name changes or spatial transformation. This process has facilitated the collection, organization and standardization of the data recorded in archival sources. In this way, it offers historians and social scientists easier access to such spatial data and enables them to conduct further relational and statistical operations and geo-spatial data analysis using these sources.

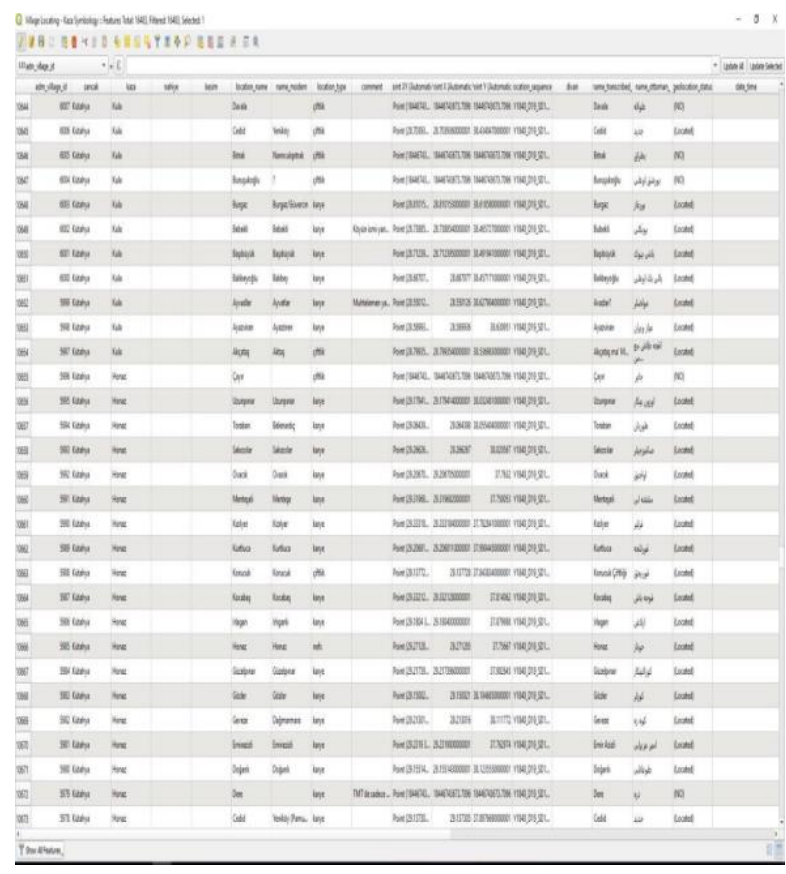

Figure 6. Data in the registers are digitised as an attribute table. Each row represents a point feature (a village), and each column a field.

Meanwhile, along with digitization, the villages' textual data are visualized in the digital platform through this geolocation process. Extracting the population registers'

2 Grigor Boykov, a former member of the UrbanOccupationsOETR, launched a stand-alone project that came out of our mid-nineteenth century geolocating efforts in Southeast Europe. His Marie Skłodowska-Curie Actions (MSCA) Individual Fellowship project POPGEO_BG (Population Geography of Bulgaria, 15001920: An Historical Spatial Analysis, popgeo.ku.edu.tr) geographical information, we mapped the villages with geometric features and displayed them on the geo-spatial web in the QGIS system. The visualization of texts incorporated multilayered sources into a generative environment. Written records of villages and their actual spatial distributions are integrated and presented in one digital platform, by which the results are produced and disseminated more visibly and efficiently. This integration also facilitates the simultaneous analysis of cartographical, socio-economic, and demographic sources by means of relational databases. Another feature of visualization is that it "opens the opportunity of exploring the spatial patterns inherent within the data in ways that were never previously possible" (Gregory \& Ell, 2007b, p. 90). As these patterns are invisible in the textual records, digital methods allow us to illustrate the connections between the geographical distribution of settlements on one hand and the demographic characteristics of these settlements on the other.

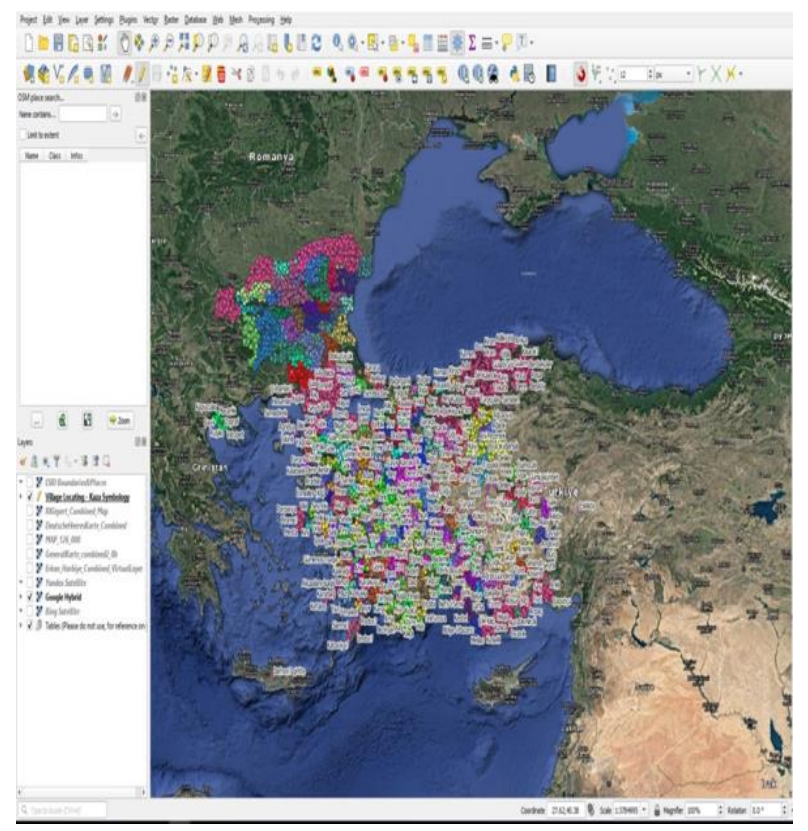

Figure 7. Data in the registers are visualised as a map dotted with point features. One point represents one village. Different colours are used for the points in each kaza to make it easier to distinguish. $^{2}$

UrbanOccupationsOETR brings together Ottoman population registers, historical maps, and cutting-edge digital tools to store and analyse geo-spatial data. The datasets collected and digitised from this project offer further digital humanities practices in Ottoman studies. Geographical Information System (GIS), as "a type of

was hosted at Koç University in 2019, which he had to abort before its completion. Yet in the limited time Boykov geolocated around 4,000 locations in today's Bulgaria which can be seen in this figure following the same data entry principles. We think our successful collaboration is a good example for generative and interoperable potentials of digital/geospatial history projects. 
software that provides a way of representing features on the Earth's surface and a suite of operations that allow the researcher to query, manipulate, visualise, and analyse these representations" (Gregory \& Geddes, 2014, p. x), is vital in the practice of geo-spatial/digital humanities. Its application in historical research, from which a new field named Historical GIS (HGIS) emerged, increased in the mid-1990s (Gregory \& Ell, 2007a, p. 1). Though a latecomer in this field, Ottoman studies are very suitable for and can benefit from HGIS/digital humanities approaches due to the vast territories, long existence, various ethno-religious communities, and diverse archival sources of the Ottoman Empire (For a recent example see, Ohanian et al., 2020; Singer, 2015). By integrating different types of historical sources such as manuscripts and maps with today's geographical technologies and tools, historians can simultaneously evaluate, compare, and analyse the huge data sources to conduct their research.

With innovations of source processing and new tools for analysis, HGIS adds fresh insights and perspectives on old research debates and can generate further research questions. HGIS approaches emphasise the spatial context and relationships of historical events. In our project, the data in the population registers are not only historical but also geographical in nature. The analytic formulation of geolocation that comprises computerised techniques and maps highlights and activates these data's spatial components, which diverts our attention to the spatial dimension of historical experiences of Ottoman people. This is much evident, especially when such data are employed in understanding the mobility of Ottoman people in the nineteenth century. In a micro-historical study that has come out of our project, such data have allowed researchers to analyse how a small mountainous village in the Ottoman Balkans, located on a land physically isolated from other settlements and not suitable for agriculture, could be integrated to the rest of the Empire by means of labour migration (Sefer et al., 2021).

Besides adding the spatial dimension to the old questions, HGIS tools' capability to process a large amount of data and present their structures facilitates our analyses of longterm and large-scale developments that could hardly be done manually. The registers provide historical pictures of individual lives, which shed light on the studies of Ottoman birth rates, mortality, conscription, taxation, family structures and migration patterns. Many studies on these topics of a specific individual, kaza or sancak, can be found in the existing literature. They are meaningful in revealing the local situation at an individual level, but they are limited to explore the local in a broader context and its relationship with the others. With the assistance of computerised analytical tools of HGIS, these individual data can be aggregated and used to construct a comprehensive picture synchronically, at the imperial level, and diachronically, tracing its transformations over generations. Moreover, the innovation of presenting data in the digital platform changes our ways of reading and seeing. The structures of points, lines and polygons encourage us to investigate the connections and correlations among data, which are less visible and less direct in the textual format. Therefore, it stimulates new research agendas. Topics regarding geographical associations, such as trade, migration, transportation networks, settlements, agriculture developments and so forth, can benefit from this spatial analysis framework a lot. For example, it is possible to conduct geo-sampling exercises to examine agricultural production or to construct multi-modal historical transport networks also by vectorising road segments in addition to settlements (Kabadayı et al., 2020, 2021).

While digital humanities promise to rejuvenate and reshape historical studies, it also bears risks and limitations. For some tasks, long-term and large-scale data often raise concerns regarding varying recording formats, techniques, inconsistency and accessibility. Those uncertainties should be considered when the database is created to keep the data's systematic characteristics and sustainability. Besides, over-reliance on technical tools might result in the simplification of complex events in human society. The debate about the epistemological conflict between digital methods and humanities is still going on. However, some scholars have optimistically pointed out that digital humanities have evolved to the qualitative wave from the quantitative wave. "The second wave is qualitative, interpretive, experiential, emotive, generative in character. It harnesses digital toolkits in the service of the humanities' core methodological strengths: attention to complexity, medium specificity, historical context, analytical depth, critique and interpretation" (Schnapp et al., 2009). The employment of digital technologies with preserving the essence of humanities research requires additional efforts from historians in their writing of the past.

\section{Conclusion}

UrbanOccupationsOETR has constructed a detailed and systematic geo-spatial dataset as part of the databases of the project. It has digitised and visualised the geographical and demographic information on Ottoman population registers by georeferencing historical maps and synthesising the registers' demographic information with retrospective data on the historical maps to create a sizeable geo-spatial database of the Anatolian settlements and populations in the 1830 s and 1840s. The data models consist of two types of data, spatial data and attribute data. Attribute data are sorted in a table; with their more quantitative feature, they usually answer "what" question, while spatial data, representing the locations by geometric features such as points, lines and polygons, usually respond to "where" questions (Gregory \& Geddes, 2014, pp. $\mathrm{x}-\mathrm{xi}$ ). In the dataset we built, every settlement, except for those whose current location could not be found, is geolocated with point features on the layer by referring to historical maps, forming spatial data. Simultaneously, every single settlement is recorded as an entry in the 
attribute table with its information of name, administrative division, coordinates, ethno-religious type of the population and male population number, etc.

The dataset is modular, updatable, and compatible with other datasets within the project to form a more comprehensive database. Our project covers a more extended period and more extensive geography than outlined in this paper. In effect, in addition to midnineteenth century Anatolia, the other phases of the project have been collecting geographic, economic and demographic data belonging to both Ottoman and postOttoman Balkan societies in the rest of the nineteenth century and the entire twentieth century. Thus, the geospatial and demographic data that we have introduced in this paper regarding Ottoman mid-nineteenth century settlements will not only allow historians to develop multidimensional perspectives to late Ottoman socio-economic history. These datasets will also pave the way for comprehensive analyses of the geo-spatial, demographic and socio-economic characteristics of historical change in the last two hundred years both in Anatolia and Southeast Europe.

\section{Acknowledgements}

Our largest thanks go to Piet Gerrits, a member of UrbanOccupationsOETR for constructing and maintaining the geospatial database and the data entry tools. We also thank all project members who contributed to planning and execution of data entry. Lastly, we are grateful to Thomas Knoll, the Head Archivist of the Cartography Department / Historical Map Archive of the Austrian Federal Office of Metrology and Surveying, for his assistance in obtaining the digital copies of the Deutsche Heereskarte, Turkey.

\section{Funding}

This work was supported by the European Research Council (ERC) project: "Industrialisation and Urban Growth from the mid-nineteenth century Ottoman Empire to Contemporary Turkey in a Comparative Perspective, 1850-2000" under the European Union's Horizon 2020 research and innovation program Grant Agreement No. 679097, acronym UrbanOccupationsOETR.

\section{References}

Gregory, I. N., \& Ell, P. S. (2007a). GIS and Its Role in Historical Research: An Introduction. In Historical GIS: Technologies, Methodologies, and Scholarship. Cambridge University Press.

Gregory, I. N., \& Ell, P. S. (2007b). Using GIS to Visualise Historical Data. In Historical GIS: Technologies,
Methodologies, and Scholarship. Cambridge University Press.

Gregory, I. N., \& Geddes, A. (2014). Introduction: From Historical GIS to Spatial Humanities: Deepening Scholarship and Broadening Technology. In I. N. Gregory \& A. Geddes (Eds.), Toward Spatial Humanities: Historical GIS and Spatial History. Indiana University Press.

Index Anatolicus. (2021). https://nisanyanmap.com

Kabadayı, M. E., Gerrits, P., \& Boykov, G. (2020). Bridging the Gap between Pre-census and Census-era Historical Data: Devising a Geo-sampling Model to Analyse Agricultural Production in the Long Run for Southeast Europe, 1840-1897. International Journal of Humanities and Arts Computing, 14(1-2), 46-63.

Kabadayı, M. E., Gerrits, P., Özkan, O., \& Koçak, T. (2021). A Preliminary Attempt to Construct a Geospatial, Multimodal Ottoman Transport Network for 1899. In Christopher. H. Roosevelt (Ed.), Spatial Webs: Mapping Anatolian Pasts for Research and the Public. Koç University Press.

Kasaba, R. (2009). A Moveable Empire: Ottoman Nomads, Migrants, and Refugees (1st ed.). University of Washington Press.

Kiepert - TDV İslâm Ansiklopedisi. TDV İslam Ansiklopedisi. Retrieved 3 April 2021, from https://islamansiklopedisi.org.tr/kiepert

Ohanian, D., Başkurt, Z. M., \& Kabadayı, M. E. (2020). An Historical Geographic Information System for Ottoman Studies: The c. 1907 Ottoman Census and Armenian Settlement in Istanbul. Turcica, 51, 255-283.

Özağaç, S. (2006). Cumhuriyet Dönemi Türk Haritacılık Tarihi. Ankara University.

Scharfe, W. (2003). German Army Map of Spain 1:50.000: 1940-1944. In Proceedings of the 21st International Cartographic Conference. Cartographic Renaissance, 2475-95. International Cartographic Association.

Schnapp, J., Presner, T., \& Lunenfeld, P. (2009). The Digital Humanities Manifesto 2.0. http://manifesto.humanities.ucla.edu/2009/05/29/thedigital-humanities-manifesto-20/

Sefer, A., Yıldız, A., \& Kabadayı, M. E. (2021). Labor Migration from Kruševo: Mobility, Ottoman Transformation, and the Balkan Highlands in the 19th Century. International Journal of Middle East Studies, 53(1), 73-87.

Shaw, S. J. (1978). The Ottoman Census System and Population, 1831-1914. International Journal of Middle East Studies, 9(3), 325-338.

Singer, A. E. (2015, December 11). Designing the Digital Ottoman Project: Six Hundred Years, Twenty-Five Languages, and Eight Alphabets. https://www.ias.edu/ideas/2015/singer-digital-ottoman

Talbert, R. J. A. (2019). Challenges of Mapping the Classical World (epub version). Routledge. 